\title{
The Relationship Between Perceived Racism/Discrimination and Health Among Black American Women: a Review of the Literature from 2003 to 2013
}

\author{
Lora L. Black • Rhonda Johnson • Lisa VanHoose
}

Received: 30 April 2014 /Revised: 11 July 2014 / Accepted: 5 August 2014 / Published online: 11 September 2014

(C) W. Montague Cobb-NMA Health Institute 2014

\begin{abstract}
Objectives The purpose of this paper was to systematically review the literature investigating the relationship between perceived racism/discrimination and health among black American women.

Methods Searches for empirical studies published from January 2003 to December 2013 were conducted using PubMed and PsycInfo. Articles were assessed for possible inclusion using the Preferred Reporting Items for Systematic Reviews and Meta-Analyses (PRISMA) 2009 framework. In addition, the Agency for Healthcare Research and Quality (AHRQ) system for rating the strength of scientific evidence was used to assess the quality of studies included in the review.

Results Nineteen studies met criteria for review. There was mixed evidence for general relationships between perceived racism/discrimination and health. Consistent evidence was found for the relationship between adverse birth outcomes, illness incidence, and cancer or tumor risk and perceived racism/discrimination. Inconsistent findings were found for the relationship between perceived racism/discrimination and heart disease risk factors. There was no evidence to support the relationship between perceived racism/ discrimination and high blood pressure.
\end{abstract}

L. L. Black · R. Johnson · L. VanHoose

University of Kansas Medical Center, 3901 Rainbow Blvd, Kansas

City, KS 66160, USA

L. L. Black

University of Kansas, 1415 Jayhawk Blvd, Lawrence, KS 66045, USA

L. L. Black $(\bowtie)$

Department of Physical Therapy and Rehabilitation Science, University of Kansas Medical Center, Kansas City, USA

e-mail: lblack2@kumc.edu
Conclusions There is mixed evidence to support the association between perceived racism/discrimination and overall objective health outcomes among black American women. The strongest relationship was seen between perceived racism/ discrimination and adverse birth outcomes. Better understanding of the relationship between health and racism/ discrimination can aid in identifying race-based risk factors developing primary prevention strategies. Future studies should aim to investigate the role of perceived racism/ discrimination as a specific chronic stressor within discrete pathogenesis models.

Keywords Women $\cdot$ Racism $\cdot$ Discrimination $\cdot$ Health

Over the years, studies have investigated the health disparities that exist in the USA, particularly between black Americans and their white counterparts [1-4]. Research has shown that blacks are at a higher risk for premature death compared to whites in America, due in part to the higher rates of diseases such as diabetes, heart disease, hypertension, and obesity [1, 5]. It is believed that a number of factors work in tandem to create these disparities, such as cultural lifestyle patterns, inherited health risks, social inequalities, and stereotype threat $[1,6]$.

In addition, there have been a number of theories suggesting that the deleterious effects of racism may contribute both directly and indirectly to these health disparities. Studies have shown the relationship between encounters of racist events, physiological activity, and health outcomes [7]. However, no systematic reviews have focused solely on its impact on black women in America. This is surprising given the evolving area of research showing the relationship between racism and low birth weight [8], heart disease [9], and breast cancer incidence $[10]$ in women. 
The purpose of this review is to critically review the existing research that focuses on the relationship between perceived racism and health outcomes among black American women over the last decade using the Preferred Reporting Items for Systematic reviews and Meta-Analyses (PRISMA) 2009 framework [11]. In addition, the Agency for Healthcare Research and Quality (AHRQ) system for rating the strength of scientific evidence [12] was used to assess the quality of studies included in the review.

\section{Methods}

\section{Defining and Measuring Racism and Discrimination}

While there is no universal definition of racism, the one that will be used for this review defines racism as "beliefs, attitudes, institutional arrangements, and acts that tend to denigrate individuals or groups because of phenotypic characteristics or ethnic group affiliation" [5]. This definition of racism includes both intergroup (racism from members of another ethnic group) and intragroup (racism from members of the same ethnic group) racism. A related concept, racial discrimination, occurs when one unfavorably distinguishes someone from others based upon race [13]. Racism is considered to be a cognitive concept involving thoughts and beliefs, while discrimination is the action that stems from those thoughts and beliefs [14]. Given the interrelatedness of these two concepts, both racism and discrimination will be examined in this review. Further, as the perception of racism and discrimination is paramount to the theoretical foundation of racism as a stressor [5], only studies that measure racism and discrimination directly at an individual level through self-report as a primary measure will be included in this review.

There are also variables that serve as mediators, including racism as a perceived stressor, coping responses, and psychological and physiological stress responses [5]. Based on the original Lazarus and Folkman model of stress [15], the effects of a potential stressor depend on the person's perception of the event as stressful and their subsequent coping responses. In the case of racism, one must first perceive the external stimuli as involving racism to be considered a stressor. Further, the coping responses employed by the person can also mediate the relationship between events and health outcomes, with maladaptive coping leading to increased stress responses and adaptive coping possibly diminishing stress responses. The repeated combination of perceived racism and maladaptive coping may result in poor health outcomes by increasing and prolonging sympathetic nervous system responses. Finally, psychological responses (e.g., anger) and physiological responses (e.g., impact on the immune system) also serve as mediators in the relationship between external stimuli and health outcomes [5]. The purpose of this review is to broadly assess the relationship between perceived racism/ discrimination and health outcomes among black women; thus, mediators and moderators will not be addressed when reviewing studies.

\section{Study Selection}

Articles were assessed for possible inclusion using the Preferred Reporting Items for Systematic Reviews and Meta-Analyses (PRISMA) 2009 framework [11]. The PRISMA framework was developed to improve the reporting of both systematic reviews and meta-analyses. It consists of a 27 -item checklist and four-phase flow diagram. The included studies were assessed using the AHRQ system for measuring the strength of scientific studies. This system evaluates eight domains of an observational research study: study question, study population, exposure of interest, outcome measurement, statistical analyses, results, discussion, and disclosure of funding or sponsorship. Each domain is assessed for meeting minimum requirements and a score (up to eight points) is given to represent the strength of the scientific evidence for each publication [12].

Studies included for review assess the relationship between perceived racism or discrimination and a variety of objective health outcomes (e.g., blood pressure, heart disease, preterm birth) among black American women. While self-reported health status is considered to be an appropriate indicator of health in some populations [16], this review was limited to more specific clinical health outcomes.

\section{Search Strategy}

PubMed and PsycInfo were searched from January 2003 to December 2013 using a combination of the following key words: "perceived discrimination," "perceived racism," "African American women," "health outcomes," "health," and "disease." Reference sections of review articles and identified studies were searched to identify additional articles for inclusion. Empirical studies that investigated health outcomes in both black men and women or women of different racial groups were considered for review if the authors gave data specifically about black women separate from black men or women of other races.

\section{Results}

\section{Search Results}

The combined searches from PubMed and PsycInfo as well as other data sources resulted in 124 studies for potential inclusion. Article titles and abstracts were reviewed, and after 
removal of duplicates and articles deemed not applicable, 66 articles were read in full. Of these articles, 47 were excluded due to not including data about women separate from men, not including data about black women separate from women of other races, using self-reported health status as a measure of health outcomes, or investigating coping mechanisms associated with perceived racism but not measures of perceived racism itself. Nineteen articles were retained for inclusion in the systematic review. See Fig. 1 for the PRISMA diagram and Table 1 for a summary table of the studies.

\section{Measuring Race}

Of the 19 studies reviewed, 11 provided information regarding how they measured participant race. All of these studies relied on self-defined race; however, the nomenclature and administration of racial definition questions varied throughout the studies. Four studies used self-defined African-American race from the study questionnaire [17-20], 2 studies used selfdefined African-American or black race from the study questionnaire [8,21], 1 study used self-defined non-Hispanic black race from the study questionnaire [22], 1 study used selfdefined non-Hispanic black/African-American race from the study questionnaire [23], and 2 studies used self-defined African-American race from their medical records [24, 25]. In addition, 1 study used self-defined race from the study questionnaire but did not provide the racial vocabulary used [26].

\section{Heart Disease Risk Factors}

There were three studies that investigated the relationship between perceived racism/discrimination and heart disease risk factors. Specific outcomes included C-reactive protein, aortic plaque area and thickness, coronary calcium [22], coronary artery calcification [23], carotid intima-media thickness (IMT), and presence of arterial plaque [27]. The Albert et al. study [22] investigated the results from 790 black women taken from the Dallas Heart Study, the Lewis et al. study [23] included 181 black women that were part of the Study of Women's Health Across the Nation (SWAN) study, and the Troxel et al. study [27] also used data obtained from the SWAN study, but the authors analyzed data from 109 black women. Results of these studies showed that there were no significant relationships between perceived discrimination and coronary calcium positive status, elevated C-reactive protein levels [22], or IMT [27]; moderate relationships were observed between chronic discrimination and presence of arterial plaque; and there were significant positive relationships between chronic discrimination and presence of coronary artery calcification [23]. All three studies in this area received an $8 / 8$ score on the AHRQ system of scientific assessment. These scores indicate that the studies assessing

Fig. 1 PRISMA diagram

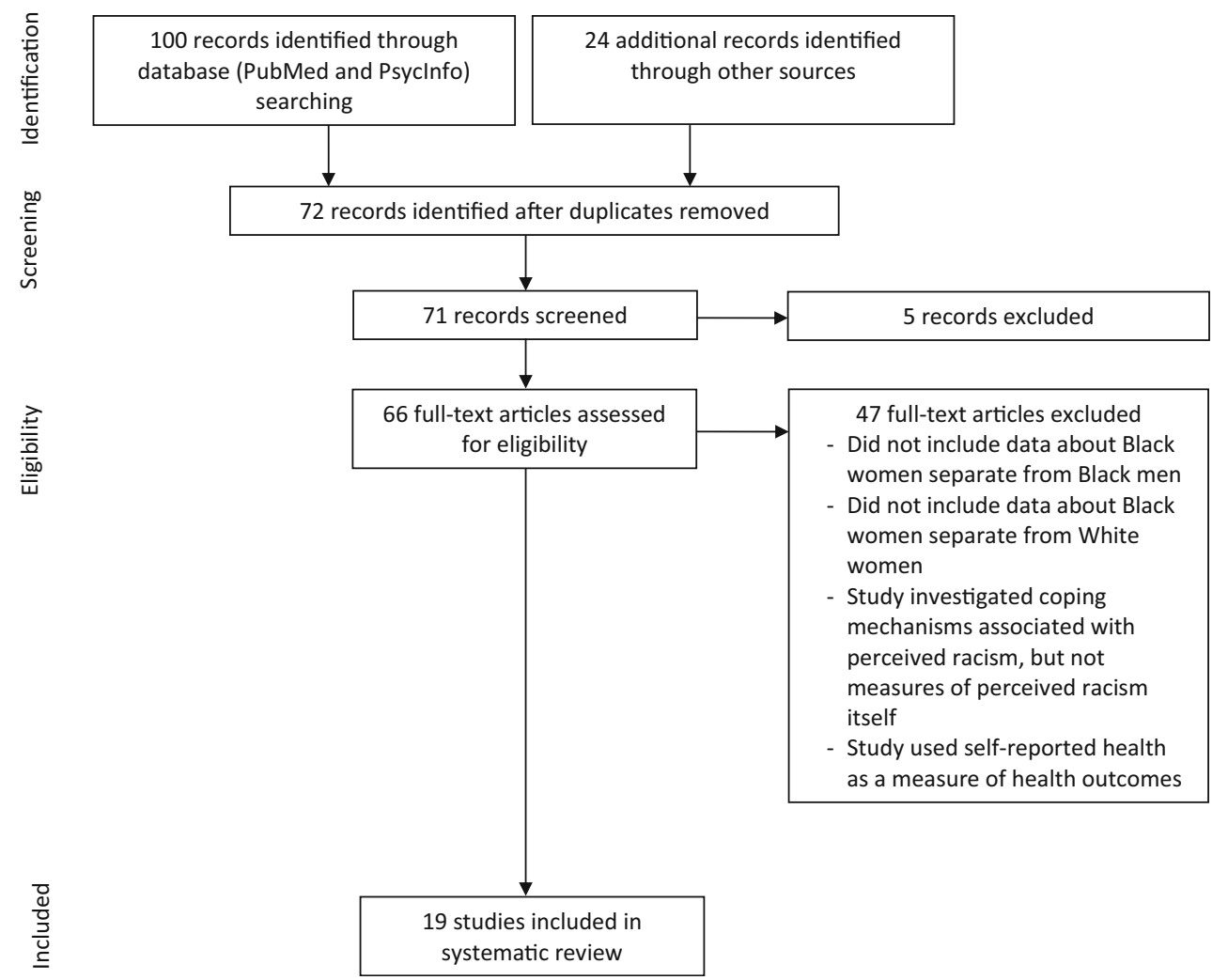




\begin{tabular}{|c|c|c|c|c|c|c|c|c|c|c|}
\hline & $\stackrel{\infty}{\infty}$ & $\stackrel{\infty}{\infty}$ & $\stackrel{\infty}{\infty}$ & $\stackrel{\infty}{\infty}$ & $\stackrel{\infty}{\infty}$ & $\stackrel{\infty}{\infty}$ & $\stackrel{\infty}{\infty}$ & $\stackrel{\infty}{\infty}$ & $\stackrel{\infty}{\infty}$ & $\stackrel{\infty}{\infty}$ \\
\hline $\begin{array}{l}\frac{\mathscr{D}}{\overline{\bar{g}}} \\
\cong\end{array}$ & 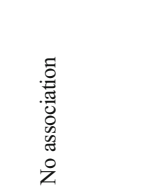 & 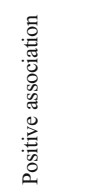 & 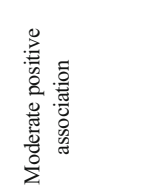 & 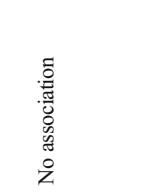 & 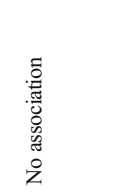 & 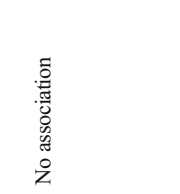 & 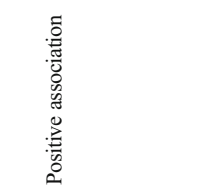 & 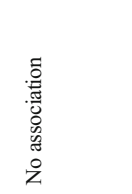 & 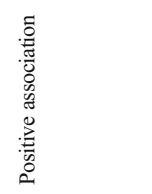 & 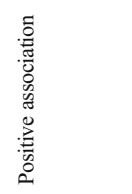 \\
\hline 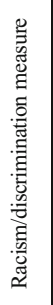 & 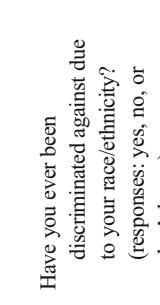 & 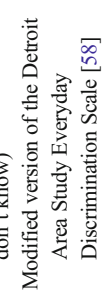 & 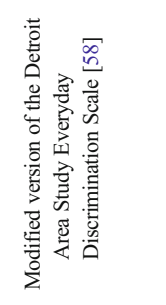 & 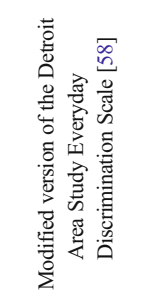 & 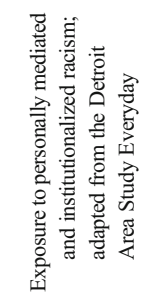 & 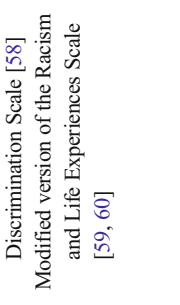 & 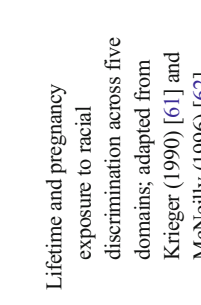 & 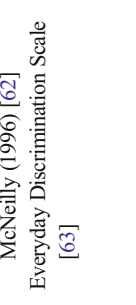 & 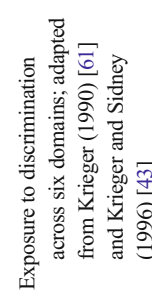 & 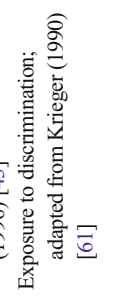 \\
\hline 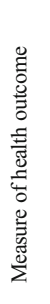 & 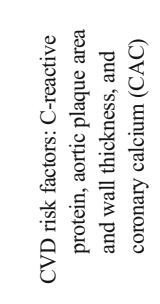 & 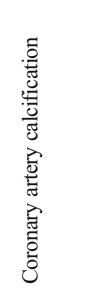 & 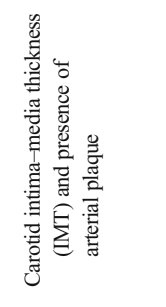 & 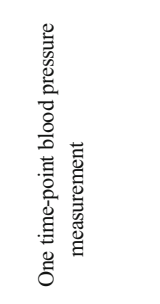 & 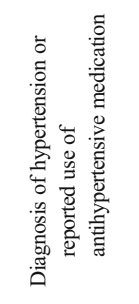 & 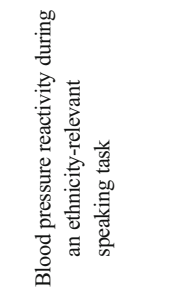 & 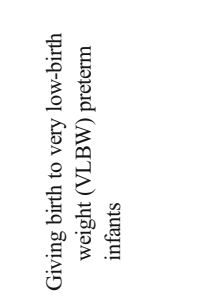 & 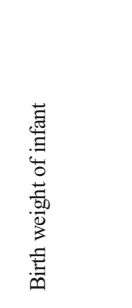 & 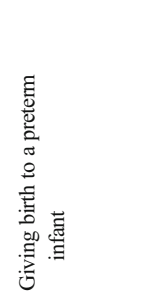 & 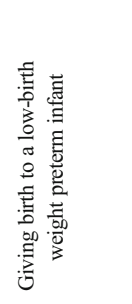 \\
\hline 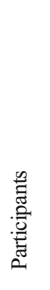 & 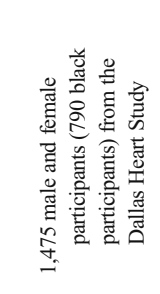 & 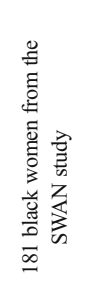 & 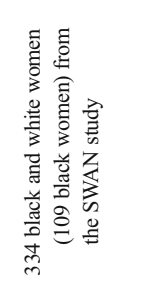 & 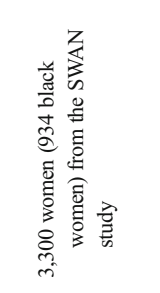 & 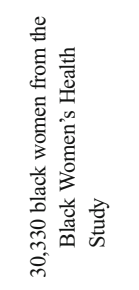 & 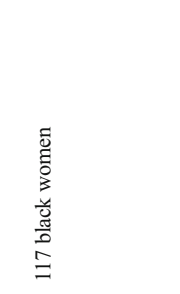 & 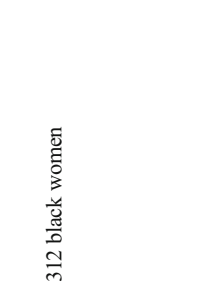 & 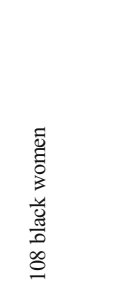 & 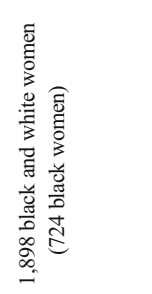 & 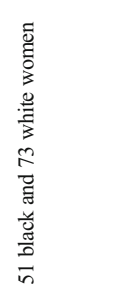 \\
\hline 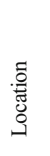 & 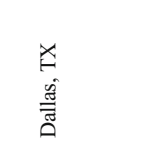 & $\overleftrightarrow{\omega}$ & 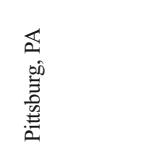 & $\overleftrightarrow{s}$ & $\overleftrightarrow{\omega}$ & 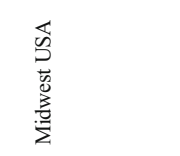 & 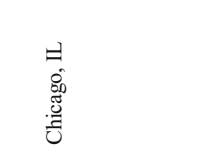 & 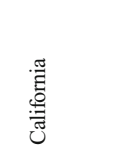 & 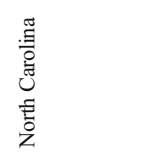 & 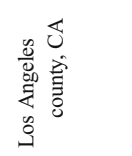 \\
\hline$\stackrel{\varrho}{\Xi}$ & 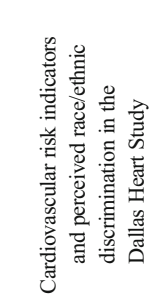 & 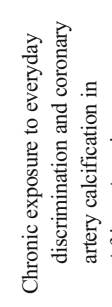 & 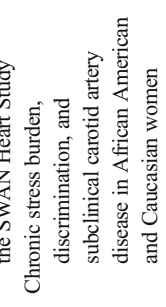 & 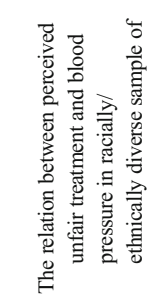 & 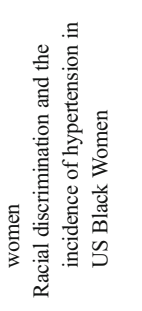 & 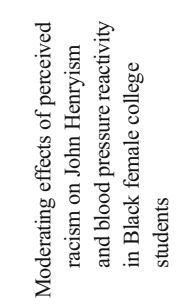 & 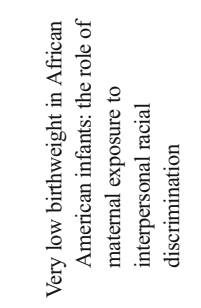 & 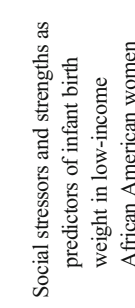 & 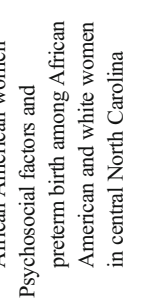 & 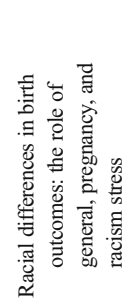 \\
\hline 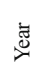 & $\stackrel{\text { ¿ }}{\circ}$ & ๕্ণ & ڤ్ & ఃั & ષ્ণ & ث્તે & 䒿 & ક્તે & ఫ্ণ & : \\
\hline $\begin{array}{l}\text { 兄 } \\
\text { 童 }\end{array}$ & 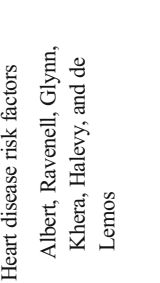 & 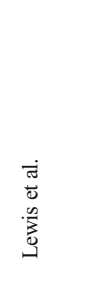 & 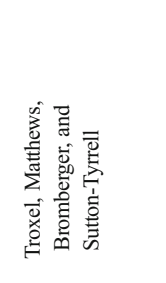 & 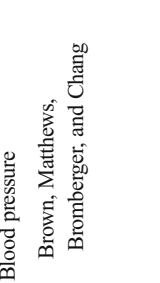 & 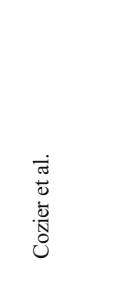 & 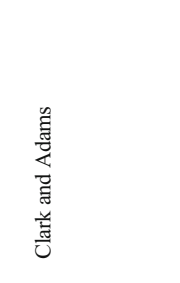 & 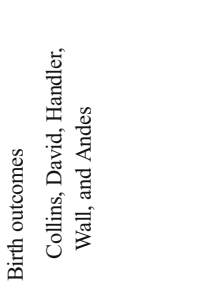 & $\frac{\partial}{\overline{\frac{2}{2}}}$ & 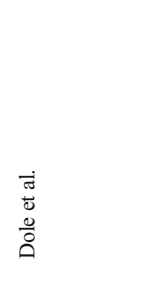 & 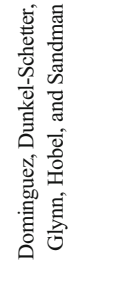 \\
\hline
\end{tabular}




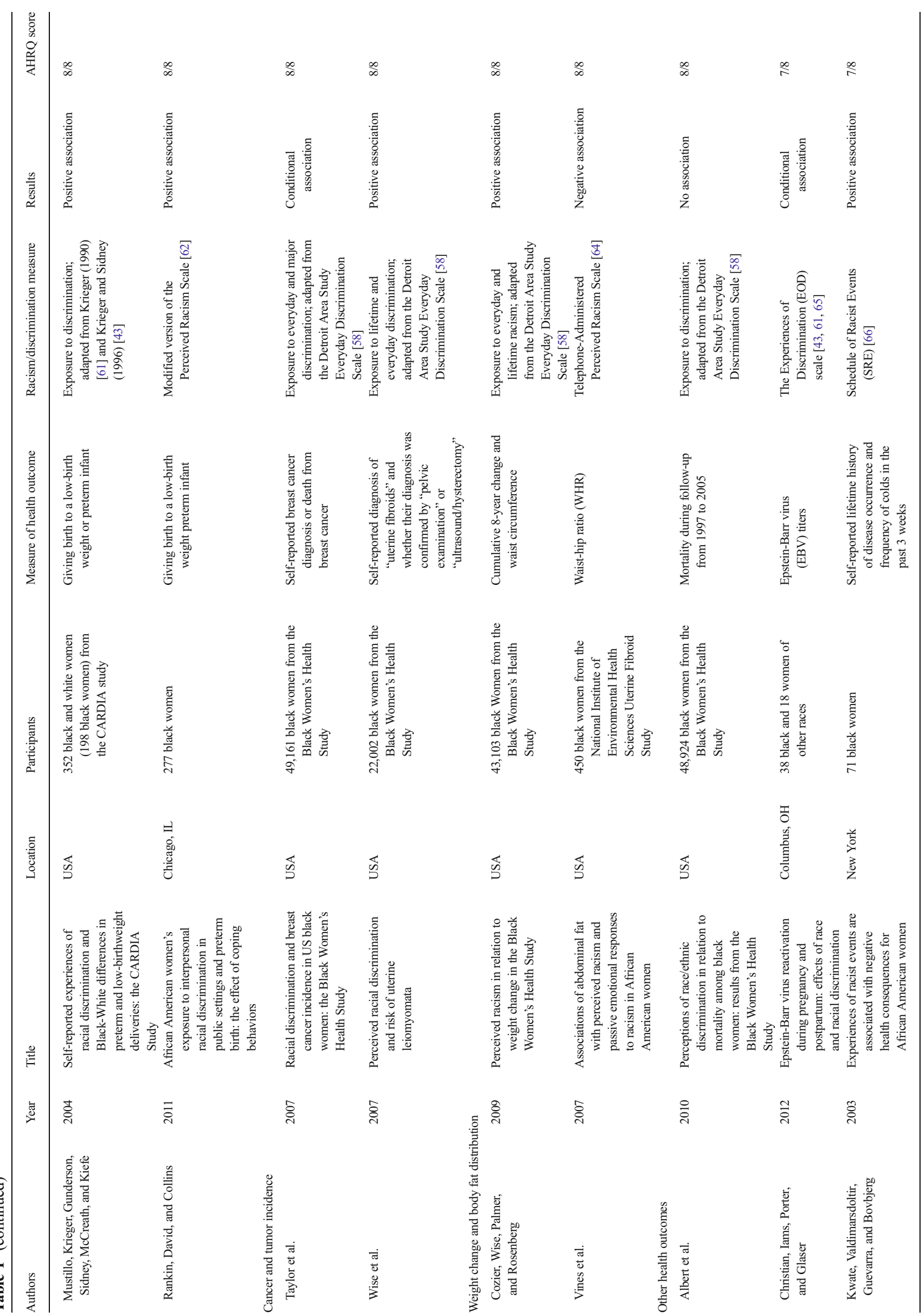


the relationship between perceived racism/discrimination and heart disease risk factors provide a good overall quality of evidence in this area. See Table 1 for AHRQ scores of individual studies.

\section{Blood Pressure}

There were three studies that investigated the relationship between perceived racism/discrimination and blood pressure. The Brown et al. study [17] analyzed data from 934 black women that were part of the SWAN study, the Cozier et al. study [28] had a sample size of 30,330 black women taken from the Black Women's Health Study, and the Clark and Adams study [29] included 117 black women from a predominately white college. Results of these studies showed that there were no significant relationships between perceived racism/discrimination and baseline blood pressure [17], blood pressure reactivity during an ethnically related speech task [29], or incidence of hypertension [28]. The studies in this area received an average score of $8 / 8$ on the AHRQ system of scientific assessment. This average score indicates that the studies assessing the relationship between perceived racism/ discrimination and blood pressure provide a good overall quality of evidence in this area.

\section{Birth Outcomes}

There were six studies that investigated the relationship between perceived racism/discrimination and adverse birth outcomes (i.e., preterm birth and low-birth weight infants). The sample sizes for these studies ranged from 51 [8] to 724 [20] black women. One study showed no significant relationship between perceived racism/discrimination and infant birth weight [19]; however, the other studies found significant associations between perceived racism/discrimination and birth weight and or/preterm birth [8, 20, 24, 25, 30]. Further, many of these studies indicated a dose-response relationship between perceived racism/discrimination and birth outcomes $[20,24,30]$. The studies in this area received an average score of $8 / 8$ on the AHRQ system of scientific assessment. This average score indicates that the studies assessing the relationship between perceived racism/discrimination and birth outcomes provide a good overall quality of evidence in this area.

\section{Cancer and Tumor Incidence}

There were two studies that investigated the relationship between perceived racism/discrimination and heart disease risk factors. The Taylor et al. [10] and Wise et al. [31] studies analyzed data from 49,161 and 22,002 black women from the Black Women's Health Study, respectively. Results of the first study [10] showed that associations between perceived racism/discrimination and breast cancer incidence were dependent on type of discrimination and age. Specifically, higher rates of breast cancer incidence were only found among women who reported discrimination on the job or in all three domains measured (e.g., housing, job, and police). In addition, there was a stronger relationship between perceived discrimination and breast cancer incidence among women younger than 50. Results of the second study [31] showed a significant, positive dose-response association between perceived racism/ discrimination and risk of uterine myomas (i.e., uterine fibroids). The studies in this area received an average score of 8/8 on the AHRQ system of scientific assessment. This average score indicates that the studies assessing the relationship between perceived racism/discrimination and cancer/tumor incidence provide a good overall quality of evidence in this area.

\section{Weight Change and Body Fat Distribution}

There were two studies that investigated the relationship between perceived racism/discrimination, weight, and body fat distribution. The study samples were 43,103 black women from the Black Women's Health Study [32] and 450 black women from the National Institute of Environmental Health Sciences Uterine Fibroid Study [21]. Results of the first study [32] showed that there was a significant positive association between perceived racism/discrimination and both weight change and waist circumference change over an 8-year period. Results from the second study [21] found a significant negative association between perceived racism/ discrimination and abdominal fat, a finding that was in direct opposition to the stated hypothesis. The studies in this area received an average score of $8 / 8$ on the AHRQ system of scientific assessment. This average score indicates that the studies assessing the relationship between perceived racism/ discrimination, weight change, and body fat distribution provide a good overall quality of evidence in this area.

\section{Other Health Outcomes}

There were three studies that investigated the relationship between perceived racism/discrimination and other health outcomes (e.g., all-cause death, Epstein-Barr virus (EBV) reactivation, and illness incidence). The Albert et al. study [33] analyzed data from 48,924 black women as part of the Black Women's Health Study, the Christian et al. study [18] included 38 black women, and the Kwate et al. study [26] included 71 black women. Results of these studies showed that there was not a significant association between perceived racism/discrimination and all-cause mortality [33], but significant positive associations were observed between perceived racism/discrimination, EBV titers during the last two trimesters of pregnancy, lifetime diagnoses of physical illnesses, and occurrence/frequency of common colds. The studies in this 
area received an average score of 7.3/8 on the AHRQ system of scientific assessment. This average score indicates that the studies assessing the relationship between perceived racism/ discrimination and other health outcomes provide a good overall quality of evidence in this area.

\section{Discussion}

The overall findings of this review suggest that there is mixed evidence for the relationship between perceived racism/ discrimination and health outcomes among black women. The strongest evidence for this relationship comes from research regarding birth outcomes. Specifically, five out of the six studies reviewed found a significant negative association between perceived racism/discrimination and infant birth weight and gestational age. Further, the results of these studies also suggest a dose-response relationship, with more frequent or lifetime exposure to discrimination having a larger effect on birth outcomes. These findings are consistent with a previous systematic review that found evidence for the positive relationship between perceived racial discrimination, low/very low birth weight, and preterm birth [34]. In addition, consistent evidence was found for the relationship between perceived racism/discrimination and illness incidence (e.g., disease occurrence, history of common colds, and EBV reactivation) but not for the possible association between perceived racial discrimination and all-cause mortality.

Further, the findings of these studies suggest a possible association between perceived racism/discrimination and cancer or tumor risk. While there is no previous research linking cancer or tumor incidence and perceived racism/discrimination, numerous studies have shown the disparities in cancer incidence and mortality between blacks and whites [3, 35-37]. This may be due to the direct physiological effects of racism and discrimination. However, the relationship may be accounted for by the association between racism/ discrimination and screening behaviors. For example, a study found that perceived racial discrimination was associated with not receiving a Pap test, but there was no association with other cancer screenings, such as mammograms and colposcopy [38].

Inconsistent findings were found for the possible relationship between heart disease risk factors and perceived racism/ discrimination. This is consistent with previous research also showing mixed evidence for the relationship between perceived racism/discrimination and heart disease risk factors among both men and women. These earlier findings range from positive associations with C-reactive protein levels [39], negative associations with coronary artery calcification [40], and no associations with multiple risk factors [22].
The results of the studies show mixed results for the association between perceived racism/discrimination, weight gain, and body fat distribution. There is a dearth of previous literature investigating the relationship between perceived racism/ discrimination and obesity measures. One study [41] found a relationship between perceived chronic discrimination and abdominal obesity among Irish, Jewish, Polish, and Italian white Americans. However, similar to the findings of the present review, this study found no association among black Americans.

Finally, there were no findings to support the relationship between perceived racism/discrimination and blood pressure in this population. These findings are somewhat inconsistent with a prior systematic review that found moderate associations between perceived racism/discrimination and blood pressure among both men and women [42]. Further, previous research investigating this relationship in black women found a positive association between perceived racial discrimination and blood pressure [43].

Overall, the results of the AHRQ assessment indicate that the methodology of the studies were good. This suggests that the mixed evidence found for the relationship between perceived racism/discrimination is likely not due to poor methodology or extraneous variables. The mixed results of this systematic review indicate that the relationship between perceived racism/discrimination and health outcomes may only be applicable to certain types of illnesses or diseases. Additional research looking at these health outcomes with mixed evidence may also help to clarify these relationships.

A number of theories may be used to explain a direct physiological relationship between perceived racism/ discrimination and health outcomes. It is hypothesized that repeated exposure to actual or perceived racism and discrimination serves as chronic stressors for blacks that can start a cascade of physiological responses resulting in disease and early death $[1,5]$. This chronic stressor may then impact health outcomes via direct physiological mechanisms. There are a number of theoretical pathogenesis models to conceptualize this relationship between stress and health, including allostatic load [44, 45], immunosuppression [46-48], and glucocorticoid-resistance models [49]. These models point to different physiological effects of stress to explain its impact on health and thus may not all be applicable to the unique stressor of perceived racism/discrimination.

While the findings of these studies may partially support a relationship between perceived racism/discrimination and health via possible physiological mechanisms, it is important to acknowledge the impact of behaviors as well. It is possible that the stress of discrimination may lead to poor coping behaviors such as tobacco and alcohol use that in turn impacts health outcomes. It is important for future studies to control for these behavioral factors as well as aim to better understand the complex relationship between perceived racism/ 
discrimination, health behaviors, and health outcomes. Further, measurement of racism/discrimination may have impacted the results of this review. Future research should aim to use consistent measures of racism and discrimination in an effort to better compare studies.

The mixed findings may also be due to the differences in coping. Defining racism and discrimination as a stressor requires that the individual perceive the event as racist or discriminatory [5]. Similarly, it may also be the way in which the individual copes with the racist event that contributes to the physiological or behavioral responses. Coping responses considered to be adaptive attenuate the psychological and physiological effects of stress and thus may moderate the effects that the stressor has on the body [5]. Assessing coping styles may help to account for the differing effects of perceived racism/ discrimination on health outcomes; however, this factor was outside the scope of this review. Further, there is no one coping style deemed effective for every individual to mitigate the effects of perceived racism. Adaptive coping styles may vary by culture, context, and individual [50], making it difficult to control for adaptive coping styles. Future research in this area should investigate both the deleterious and protective effects of different coping styles on health outcomes.

The results of this systematic review are limited by the data obtained from the individual studies, such as method of measuring race. All of the studies that described how they defined race used self-defined race to classify women as black or African-American. No studies aimed to further delineate black or African-American into different groups, such as those of black Caribbean or Hispanic black descent. The collapsing of different racial categories is a weakness of this review as it restricts the ability to investigate intragroup differences between those self-described as black or African-American. Future research in this area should aim to provide additional race categories in an effort to identify differences among those broadly categorized as black or African-American.

In addition, a weakness of this systematic review is that it includes data from studies with a large range of sample sizes. The studies reviewed included sample sizes ranging from 38 [18] to 49,161 [10] black women. Caution should be used when comparing the results of studies with such differing sample sizes; however, this review included studies of all sizes in an effort to provide a comprehensive review of the literature. Limiting a review to studies with larger sample sizes may have resulted in the focus on only specific health outcomes while disregarding others. While the smaller studies may not have as much statistical power, the findings of such studies are of interest and provide a basis for larger studies about the relationship between perceived racism/discrimination and these health outcomes.

This systematic review suggests that perceived racism and discrimination may impact a number of health outcomes among black women; however, there are a number of areas that lack consistent evidence and would benefit from continued research.
Very few studies investigated the relationship between perceived racism/discrimination and health outcomes within a specific pathogenesis model. Given that the different models may be more appropriate for some health outcomes compared to others, it is important to examine relationships within the framework of these different models. For example, research has suggested that inflammation may play a part in the occurrence of spontaneous preterm birth [51, 52]. The glucocorticoid-resistance model states that chronic stress may decrease the immune response and increase inflammation over time by diminishing the immune system's sensitivity to glucocorticoid hormones normally involved in regulating the inflammation response. This inability to regulate can then result in excess inflammation throughout the body [49]. Future studies could investigate perceived racism/ discrimination as a chronic stressor that impacts health outcomes such as preterm birth via specific pathogenesis models such as this.

While past research has investigated the relationship between chronic stressors and health, future research should extend this research to examine perceived racism/ discrimination as a specific type of chronic stressor. This is especially important among black women, as some theorists have suggested that they may identify with multiple minority groups and in turn experience higher levels of distress from the combination of racial and gender discrimination [53-55]. By better understanding the unique role of perceived racism and discrimination in health outcomes, we can identify possible race-based risk factors for diseases and primary prevention. This knowledge can also aid in reducing medical mistrust, which can have a direct effect on understanding of, and adherence to, medical advice that may impact satisfaction with care and quality of life [56, 57].

Conflict of Interest Dr. VanHoose is supported by the Eunice Kennedy Shriver National Institute of Child Health \& Development of the National Institutes of Health under Award number K12HD052027.

Dr. Johnson and Ms. Black declare that they have no conflict of interest.

Note: Research reported in this publication was supported by the Eunice Kennedy Shriver National Institute of Child Health \& Development of the National Institutes of Health under Award Number K12HD052027. The content is solely the responsibility of the authors and does not necessarily represent the official views of the National Institutes of Health.

Informed Consent Statement No animal or human studies were carried out by the authors for this article.

\section{References}

1. Mays VM, Cochran SD, Barnes NW. Race, race-based discrimination, and health outcomes among African Americans. Annu Rev Psychol. 2007;58:201-25. 
2. Williams DR, Mohammed SA. Discrimination and racial disparities in health: evidence and needed research. J Behav Med. 2009;32(1): 20-47.

3. Ward E, Jemal A, Cokkinides V, Singh GK, Cardinez C, Ghafoor A, et al. Cancer disparities by race/ethnicity and socioeconomic status. CA Cancer J Clin. 2004;54(2):78-93.

4. Geronimus AT, Bound J, Waidmann TA, Hillemeier MM, Burns PB. Excess mortality among blacks and whites in the United States. N Engl J Med. 1996;335(21):1552-8.

5. Clark R, Anderson NB, Clark VR, Williams DR. Racism as a stressor for African Americans: a biopsychosocial model. Am Psychol. 1999;54(10):805-16.

6. Burgess DJ, Warren J, Phelan S, Dovidio J, van Ryn M. Stereotype threat and health disparities: what medical educators and future physicians need to know. J Gen Intern Med. 2010;25(2):169-77.

7. Harrell JP, Hall S, Taliaferro J. Physiological responses to racism and discrimination: an assessment of the evidence. Am J Public Health. 2003;93(2):243-8.

8. Dominguez TP, Dunkel-Schetter C, Glynn LM, Hobel C, Sandman CA. Racial differences in birth outcomes: the role of general, pregnancy, and racism stress. Health Psychol. 2008;27(2):194-203.

9. Saban KL, Hoppensteadt D, Bryant FB, DeVon HA. Social determinants and heat shock protein-70 among African American and nonHispanic white women with atherosclerosis: a pilot study. Biological Research for Nursing. 2013.

10. Taylor TR, Williams CD, Makambi KH, Mouton C, Harrell JP, Cozier Y, et al. Racial discrimination and breast cancer incidence in US black women: the Black Women's Health Study. Am J Epidemiol. 2007;166(1):46-54.

11. Moher D, Liberati A, Tetzlaff J, Altman DG. Preferred reporting items for systematic reviews and meta-analyses: the PRISMA statement. Ann Intern Med. 2009;151(4):264-9.

12. West SL, King V, Carey TS, Lohr KN, McKoy N, Sutton SF, et al. Systems to rate the strength of scientific evidence. Agency for Healthcare Research and Quality, US Department of Health and Human Services; 2002.

13. Krieger N. Embodying inequality: a review of concepts, measures, and methods for studying health consequences of discrimination. Int J Health Serv. 1999;29(2):295-352.

14. Gee GC, Ro A. Racism and discrimination. In: Trinh-Shevrin C, Islam NS, Rey MJ, editors. Asian American communities and health: context, research, policy, and action. San Francisco, CA: JosseyBass; 2009. p. 364-402.

15. Lazarus RS, Folkman S. Stress, appraisal, and coping. New York: Springer Publishing Company; 1984.

16. Miilunpalo S, Vuori I, Oja P, Pasanen M, Urponen H. Self-rated health status as a health measure: the predictive value of selfreported health status on the use of physician services and on mortality in the working-age population. J Clin Epidemiol. 1997;50(5): 517-28.

17. Brown C, Matthews KA, Bromberger JT, Chang Y. The relation between perceived unfair treatment and blood pressure in a racially/ ethnically diverse sample of women. Am J Epidemiol. 2006;164(3): 257-62.

18. Christian LM, Iams JD, Porter K, Glaser R. Epstein-Barr virus reactivation during pregnancy and postpartum: effects of race and racial discrimination. Brain Behav Immun. 2012;26:1280-7.

19. Dailey DE. Social stressors and strengths as predictors of infant birth weight in low-income African American women. Nurs Res. 2009;58(5):340-7.

20. Dole N, Savitz DA, Siega-Riz AM, Hertz-Picciotto I, McMahon MJ, Buekens P. Psychosocial factors and preterm birth among African American and White women in central North Carolina. Am J Public Health. 2004;94(8):1358-65.

21. Vines AI, Baird DD, Stevens J, Hertz-Picciotto I, Light KC, McNeilly M. Associations of abdominal fat with perceived racism and passive emotional responses to racism in African American women. J Inf. 2007;97(3):526-30.

22. Albert MA, Ravenell J, Glynn RJ, Khera A, Halevy N, de Lemos JA. Cardiovascular risk indicators and perceived race/ethnic discrimination in the Dallas Heart Study. Am Heart J. 2008;156(6):1103-9.

23. Lewis TT, Everson-Rose SA, Powell LH, Matthews KA, Brown C, Karavolos K, et al. Chronic exposure to everyday discrimination and coronary artery calcification in African-American women: the SWAN Heart Study. Psychosom Med. 2006;68(3):362-8.

24. Collins JW, David RJ, Handler A, Wall S, Andes S. Very low birthweight in African American infants: the role of maternal exposure to interpersonal racial discrimination. Am J Public Health. 2004;94(12):2132-8.

25. Rankin KM, David RJ, Collins Jr JW. African American women's exposure to interpersonal racial discrimination in public settings and preterm birth: the effect of coping behaviors. Ethn Dis. 2011;21(3): $370-6$.

26. Kwate NOA, Valdimarsdottir HB, Guevarra JS, Bovbjerg DH. Experiences of racist events are associated with negative health consequences for African American women. J Natl Med Assoc. 2003;95(6):450-60.

27. Troxel WM, Matthews KA, Bromberger JT, Sutton-Tyrrell K. Chronic stress burden, discrimination, and subclinical carotid artery disease in African American and Caucasian women. Health Psychol. 2003;22(3):300-9.

28. Cozier Y, Palmer JR, Horton NJ, Fredman L, Wise LA, Rosenberg L. Racial discrimination and the incidence of hypertension in US black women. Ann Epidemiol. 2006;16(9):681-7.

29. Clark R, Adams JH. Moderating effects of perceived racism on John Henryism and blood pressure reactivity in Black female college students. Ann Behav Med. 2004;28(2):126-31.

30. Mustillo S, Krieger N, Gunderson EP, Sidney S, McCreath H, Kiefe CI. Self-reported experiences of racial discrimination and Black-White differences in preterm and low-birthweight deliveries: the CARDIA Study. Am J Public Health. 2004;94(12):2125-31.

31. Wise LA, Palmer JR, Cozier YC, Hunt MO, Stewart EA, Rosenberg L. Perceived racial discrimination and risk of uterine leiomyomata. Epidemiology. 2007;18(6):747.

32. Cozier YC, Wise LA, Palmer JR, Rosenberg L. Perceived racism in relation to weight change in the Black Women's Health Study. Ann Epidemiol. 2009;19(6):379-87.

33. Albert MA, Cozier Y, Ridker PM, Palmer JR, Glynn RJ, Rose L, et al. Perceptions of race/ethnic discrimination in relation to mortality among black women: results from the Black Women's Health Study. Arch Intern Med. 2010;170(10):896-904.

34. Giurgescu C, McFarlin BL, Lomax J, Craddock C, Albrecht A. Racial discrimination and the Black-White gap in adverse birth outcomes: a review. J Midwifery Womens Health. 2011;56(4):36270.

35. Agrawal S, Bhupinderjit A, Bhutani MS, Boardman L, Nguyen C, Romero Y, et al. Colorectal cancer in African Americans. Am J Gastroenterol. 2005;100(3):515-23.

36. Williams DR, Jackson PB. Social sources of racial disparities in health. Health Aff. 2005;24(2):325-34.

37. Palmer RC, Schneider EC. Social disparities across the continuum of colorectal cancer: a systematic review. Cancer Causes Control. 2005;16(1):55-61.

38. Mouton CP, Carter-Nolan PL, Makambi KH, Taylor TR, Palmer JR, Rosenberg L, et al. Impact of perceived racial discrimination on health screening in black women. J Health Care Poor Underserved. 2010;21(1):287-300.

39. Lewis TT, Aiello AE, Leurgans S, Kelly J, Barnes LL. Self-reported experiences of everyday discrimination are associated with elevated C-reactive protein levels in older African-American adults. Brain Behav Immun. 2010;24(3):438-43. 
40. Everage NJ, Gjelsvik A, McGarvey ST, Linkletter CD, Loucks EB. Inverse associations between perceived racism and coronary artery calcification. Ann Epidemiol. 2012;22(3):183-90.

41. Hunte HE, Williams DR. The association between perceived discrimination and obesity in a population-based multiracial and multiethnic adult sample. Am J Public Health. 2009;99(7):1285-92.

42. Williams DR, Neighbors H. Racism, discrimination and hypertension: evidence and needed research. Ethn Dis. 2001;11(4):800-16.

43. Krieger N, Sidney S. Racial discrimination and blood pressure: the CARDIA Study of young black and white adults. Am J Public Health. 1996;86(10):1370-8.

44. Korte SM, Koolhaas JM, Wingfield JC, McEwen BS. The Darwinian concept of stress: benefits of allostasis and costs of allostatic load and the trade-offs in health and disease. Neurosci Biobehav Rev. 2005;29(1):3-38.

45. McEwen BS. Stress, adaptation, and disease: allostasis and allostatic load. Ann N Y Acad Sci. 1998;840(1):33-44.

46. Cohen S, Herbert TB. Health psychology: psychological factors and physical disease from the perspective of human psychoneuroimmunology. Annu Rev Psychol. 1996;47(1):113-42.

47. Maier SF, Watkins LR, Fleshner M. Psychoneuroimmunology: the interface between behavior, brain, and immunity. Am Psychol. 1994;49(12):1004-17.

48. Segerstrom SC, Miller GE. Psychological stress and the human immune system: a meta-analytic study of 30 years of inquiry. Psychol Bull. 2004;130(4):601-30.

49. Miller GE, Cohen S, Ritchey AK. Chronic psychological stress and the regulation of pro-inflammatory cytokines: a glucocorticoidresistance model. Health Psychol. 2002;21(6):531-41.

50. Pascoe EA, Smart RL. Perceived discrimination and health: a metaanalytic review. Psychol Bull. 2009;135(4):531.

51. Wadhwa PD, Culhane JF, Rauh V, Barve SS, Hogan V, Sandman CA, et al. Stress, infection and preterm birth: a biobehavioural perspective. Paediatr Perinat Epidemiol. 2001;15(s2):17-29.

52. Romero R, Espinoza J, Gonçalves L, Kusanovic JP, Friel L, Hassan $\mathrm{S}$, editors. The role of inflammation and infection in preterm birth. Seminars in reproductive medicine; 2007: Thieme.

53. Jones HL, Cross WE, DeFour DC. Race-related stress, racial identity attitudes, and mental health among Black women. J Black Psychol. 2007;33(2):208-31.
54. Thomas AJ, Witherspoon KM, Speight SL. Gendered racism, psychological distress, and coping styles of African American women. Cult Divers Ethn Minor Psychol. 2008;14(4):307.

55. St. Jean Y, Feagin JR. Double burden: Black women and everyday racism. Armonk, NY: M. E. Sharpe; 1998.

56. Thompson HS, Valdimarsdottir HB, Winkel G, Jandorf L, Redd W. The Group-Based Medical Mistrust Scale: psychometric properties and association with breast cancer screening. Prev Med. 2004;38(2): 209-18.

57. LaVeist TA, Nickerson KJ, Bowie JV. Attitudes about racism, medical mistrust, and satisfaction with care among African American and white cardiac patients. Med Care Res Rev. 2000;57(4 suppl):146-61.

58. Williams DR, Yu Y, Jackson JS, Anderson NB. Racial differences in physical and mental health socio-economic status, stress and discrimination. J Health Psychol. 1997;2(3):335-51.

59. Harrell SP, Merchant MA, Young SA. Psychometric properties of the Racism and Life Experiences Scales (RaLES). Annual Convention of the American Psychological Association; Chicago, IL1997.

60. Harrell SP. The racism and life experience scales. Unpublished manuscript. 1997.

61. Krieger N. Racial and gender discrimination: risk factors for high blood pressure? Soc Sci Med. 1990;30(12):1273-81.

62. McNeilly MD, Anderson NB, Armstead CA, Clark R, Corbett M, Robinson EL, et al. The perceived racism scale: a multidimensional assessment of the experience of white racism among African Americans. Ethn Dis. 1996;6(1-2):154-66.

63. Forman TA, Williams DR, Jackson JS, Gardner C. Race, place, and discrimination. Perspect Soc Probl. 1997;9:231-61.

64. Vines AI, McNeilly MD, Stevens J, Hertz-Picciotto I, Bohlig M, Baird DD. Development and reliability of a Telephone-Administered Perceived Racism Scale (TPRS): a tool for epidemiological use. Ethn Dis. 2001;11(2):251-62.

65. Krieger N, Smith K, Naishadham D, Hartman C, Barbeau EM. Experiences of discrimination: validity and reliability of a selfreport measure for population health research on racism and health. Soc Sci Med. 2005;61(7):1576-96.

66. Landrine H, Klonoff EA. The schedule of racist events: a measure of racial discrimination and a study of its negative physical and mental health consequences. J Black Psychol. 1996;22(2):144-68. 